\title{
Comparison of Concrete Properties determined by Destructive and Non-Destructive Tests
}

\author{
Siddharth Shankar ${ }^{1,2}$, Hikmat Raj Joshi ${ }^{2}$ \\ ${ }^{I}$ Central Material Testing Laboratory, Institute of Engineering, TU, Pulchowk, Lalitpur, Nepal \\ ${ }^{2}$ Department of Civil Engineering, Central Campus, Pulchowk, IOE, TU, Lalitpur, Nepal \\ Corresponding Email: siddharth@ioe.edu.np, hjoshi@ioe.edu.np
}

\begin{abstract}
Concrete is most widely used construction material worldwide .Strength of a concrete structure may have to be assessed without causing physical damage to it due to various reasons like its monumental importance or the legal dispute on whether the strength of the concrete in the structure is satisfactory enough or not. Non destructive test (NDT) is one of the various ways to estimate strength of the concrete without inflicting any significant damage to it. In this paper comparison between the actual strength of a concrete by destructive test (DT) method and that by NDT method has been done. The methods used are Schmidt Hammer $(\mathrm{SH})$ (or rebound hammer) and ultrasonic pulse velocity (UPV) as NDTs and test by compression testing machine (CTM) as DT. In this study separate comparisons have been done for two NDTs and a procedure to follow while estimating strength of concrete by NDT has been recommended.
\end{abstract}

Keywords: Concrete, Non destructive test (NDT), Destructive test (DT), Schmidt Hammer (SH), Rebound Hammer (RH), Ultrasonic Pulse Velocity (UPV), Compressive test, Compressive Testing Machine (CTM), Compressive Strength, Concrete Cubes, Concrete Cylinders, Structural Safety, Structural Health, Core Samples.

\section{Introduction}

Recent development in concrete is high strength concrete, which is mixture of cement, sand, aggregate, water and admixtures. The compressive strength of concrete is its one of the most valuable property. To determine compressive strength of concrete is a major task of engineers/researchers for existing concrete structures. There are two aspects of determination of compressive strength of concrete which are destructive tests (DT) and non destructive tests (NDT). The DT of concrete is not always appropriate method to find compressive strength of concrete and concrete structures because it affects the durability and lifespan of concrete. Hence, the NDT method is only one predominant method to find the strength of existing concrete and concrete structures, and to judge the quality of concrete. The NDT method is direct and easy tool to find in situ compressive strength of concrete. The NDT test methods include rebound hammer, ultrasonic pulse velocity test, penetration test, radiography test, sonic integrity tests etc. There are two distinct areas in civil engineering works where it has to be relied on NDT for practical and theoretical purposes. The first ones are the old monumental structural systems like ancient temples and edifices. The second ones are the buildings which are coming up so fast in the urban areas as the result of burgeoning housing industry, which badly needs quality control for mass safety and security of the people.

The properties, characteristics and qualities of these two groups of structural systems can be quickly and systematically recorded, if the tests performed are NDT ones. However, for the reliability of these results and records can be proven only if the relationship between these tests 
and the DT which are more realistic and reliable but not always possible has been established. The relationship between the two types of tests which the research work is to establish will provide a series of vital data and solve a series of problems in assessment of the properties, characteristics and vulnerability of the standing structural systems [12]. However, none of these tests can be used independently to yield reliable quantitative results. Out of these NDT test methods, combination of two or more NDT yields results of acceptable levels. For instance, in case of a historical monument, which is already standing for hundreds of years or in case of a structural system which has already been constructed but requires verification of the properties and characteristics of its material, elements or the system as a whole, the DT is not the best method to apply.

One of the challenging and virgin areas in testing civil engineering materials and structures is to establish relationship between the results from DT and NDT [13]. The usefulness and reliability of the results of NDT when DT is not practically possible can only be verified only if/when the relationship between the two tests has been properly established.

\section{Literature Review}

A series of related M Sc theses of the Tribhuvan University, Institute of Engineering, other national and international journals as well as books have been studied. Out of these, some of the significant works are mentioned below:

Aydin and Saribiyik [3] have attempted to establish the relationship between rebound numbers (N) and crushing strengths of cubes and core samples from elements of structures. The data plotted were compared by doing linear regression. It has been found that the variations in correlation were higher for older (than ninety days) concrete. A table and chart of transformation factors for old concrete based upon strengths have been suggested.

Pattanaika [21] suggested at least two independent methods of different equipment of NDT should be used to determine the compressive strength of concrete. By using correlation curves, he obtained a correction factor that can be used for quick assessment of quality of the concrete by rebound hammer. He also established correlation between each pair of NDT instruments for assessment of compressive strength of concrete at necessary location which would be necessary for structural health monitoring.

Hannachi and Gueteche [7] have studied both single and multiple variable equations involving $\mathrm{SH}$ and pulse velocity meter. They have compiled works done by various researchers till now and have compiled them in a tabular form (Table 1). 
Table 1: Equations of existing relationship used for compressive strength estimation of concrete

\begin{tabular}{|c|c|c|c|c|}
\hline \multicolumn{5}{|c|}{ Single-variable equations } \\
\hline $\begin{array}{l}\text { Eq. } \\
\text { No. }\end{array}$ & Equation & Dimensions & Reference & RMSE \\
\hline 1 & $\mathrm{f}_{\mathrm{c}}=21.575 \times \mathrm{L}-72.276$ & $\begin{array}{l}\mathrm{f}_{\mathrm{c}}[\mathrm{MPa}] \\
\mathrm{L}[\mathrm{cm}]\end{array}$ & $\begin{array}{l}\text { NDT Windsor } \\
\text { Sys. Inc. (1994) }\end{array}$ & 3.7813 \\
\hline 2 & $\mathrm{f}_{\mathrm{c}}=1.2 \times 10^{-5} \times \mathrm{V}^{1.7447}$ & $\begin{array}{l}\mathrm{f}_{\mathrm{c}}[\mathrm{MPa}] \\
\mathrm{V}[\mathrm{km} / \mathrm{s}]\end{array}$ & $\begin{array}{l}\text { Kheder } 1 \\
(1998)\end{array}$ & 6.0974 \\
\hline 3 & $\mathrm{f}_{\mathrm{c}}=0.4030 \times \mathrm{R}^{1.2083}$ & $\mathrm{f}_{\mathrm{c}}[\mathrm{MPa}]$ & $\begin{array}{l}\text { Kheder } 2 \\
\text { (1998) }\end{array}$ & 2.1651 \\
\hline 4 & $f_{c}=36.72 \times V-129.077$ & $\begin{array}{l}\mathrm{f}_{\mathrm{c}}[\mathrm{MPa}] \\
\mathrm{V}[\mathrm{km} / \mathrm{s}]\end{array}$ & $\begin{array}{l}\text { Quasrawi } 1 \\
\text { (2000) }\end{array}$ & 3.6981 \\
\hline 5 & $\mathrm{f}_{\mathrm{c}}=1.353 \times \mathrm{R}-17.393$ & $\mathrm{f}_{\mathrm{c}}[\mathrm{MPa}]$ & $\begin{array}{l}\text { Quasrawi } 1 \\
\text { (2000) }\end{array}$ & 2.8152 \\
\hline 6 & $f_{c}=-5333+5385 \times L$ & $\begin{array}{l}\mathrm{f}_{\mathrm{c}}[\mathrm{MPa}] \\
\mathrm{L}[\mathrm{in}]\end{array}$ & Malhotra et al. & 2.2128 \\
\hline \multicolumn{5}{|c|}{ Multi-variable equations } \\
\hline $\begin{array}{l}\text { Eq. } \\
\text { No. }\end{array}$ & Equation & Dimensions & Reference & RMSE \\
\hline 7 & $\begin{array}{l}\mathrm{f}_{\mathrm{c}}=-25.568+0.000635 \times \mathrm{R} 3+ \\
8.397 \mathrm{~V}\end{array}$ & $\begin{array}{l}\mathrm{f}_{\mathrm{c}}[\mathrm{MPa}] \\
\mathrm{V}[\mathrm{km} / \mathrm{s}]\end{array}$ & $\begin{array}{l}\text { Bellander } \\
\text { (1979) }\end{array}$ & 2.2128 \\
\hline 8 & $f_{c}=-24.668+1.427 \times R+0.0294 V 4$ & $\begin{array}{l}\mathrm{f}_{\mathrm{c}}[\mathrm{MPa}] \\
\mathrm{V}[\mathrm{km} / \mathrm{s}]\end{array}$ & $\begin{array}{l}\text { Meynink et al. } \\
\text { (1979) }\end{array}$ & 7.0654 \\
\hline 9 & $f_{c}=0.745 \times R+0.951 \times V-0.544$ & $\begin{array}{l}\mathrm{f}_{\mathrm{c}}[\mathrm{MPa}] \\
\mathrm{V}[\mathrm{m} / \mathrm{s}]\end{array}$ & Tanigawa et al. & 2. 1000 \\
\hline 10 & $f_{c}=[R /(18.6+0.019 \times R+0.515 \times V)]$ & $\begin{array}{l}\mathrm{f}_{\mathrm{c}}\left[\mathrm{kg} / \mathrm{cm}^{2}\right] \\
\mathrm{V}[\mathrm{km} / \mathrm{s}]\end{array}$ & $\begin{array}{l}\text { Postacioglu } \\
\quad(1985)\end{array}$ & 3.7617 \\
\hline 11 & $11 \mathrm{f}_{\mathrm{c}}=18.6 \times \mathrm{e}^{(0.019 \times \mathrm{R}+0515 \mathrm{~V})}$ & $\begin{array}{l}\mathrm{f}_{\mathrm{c}}\left[\mathrm{kg} / \mathrm{cm}^{2}\right] \\
\mathrm{V}[\mathrm{km} / \mathrm{s}]\end{array}$ & $\begin{array}{l}\text { Arioglu et al. } \\
\qquad(1991)\end{array}$ & 2.9205 \\
\hline 12 & $f_{c}=10^{3.119}\left(\sqrt{\log R^{3} \times V^{4}}\right)^{-5.890}$ & $\begin{array}{l}\mathrm{f}_{\mathrm{c}}\left[\mathrm{kg} / \mathrm{cm}^{2}\right] \\
\mathrm{V}[\mathrm{km} / \mathrm{s}]\end{array}$ & $\begin{array}{l}\text { Arioglu et al. } \\
\quad(1994)\end{array}$ & 4.2305 \\
\hline 13 & $f_{c}=-39.570+1.532 \times R+5.0 .614 \times V$ & $\begin{array}{l}\mathrm{f}_{\mathrm{c}}\left[\mathrm{kg} / \mathrm{cm}^{2}\right] \\
\mathrm{V}[\mathrm{km} / \mathrm{s}]\end{array}$ & $\begin{array}{l}\text { Raymar et al. } \\
\text { (1996) }\end{array}$ & 7.5910 \\
\hline 14 & $\mathrm{f}_{\mathrm{c}}=0.00153 \times\left(\mathrm{R}^{3} \times \mathrm{V}^{4}\right)$ & $\begin{array}{l}\mathrm{f}_{\mathrm{c}}\left[\mathrm{kg} / \mathrm{cm}^{2}\right] \\
\mathrm{V}[\mathrm{km} / \mathrm{s}]\end{array}$ & $\begin{array}{l}\text { Arioglu et al. } \\
\quad(1996)\end{array}$ & 11.1623 \\
\hline 15 & $\mathrm{f}_{\mathrm{c}}=0.0158 \times \mathrm{V}^{0.4254} \times \mathrm{R}^{1.1171}$ & $\begin{array}{l}\mathrm{f}_{\mathrm{c}}\left[\mathrm{kg} / \mathrm{cm}^{2}\right] \\
\mathrm{V}[\mathrm{km} / \mathrm{s}]\end{array}$ & $\begin{array}{l}\text { Kheder } 3 \\
\text { (1998) }\end{array}$ & 2.1375 \\
\hline
\end{tabular}




\section{Experimental Investigation}

For NDT two equipment were used for SH and UPV testing. For SH and UPV testing W-M-250 [4] and Pundit Lab Proceq, [20] respectively were used. For DT the testing machine used was Compression Testing Machine Mark XII (Compression Testing Machine Mark XII, N D). The objects used for testing were standard sized samples $(150 \mathrm{~mm}$ cubes, $100 \mathrm{~mm}$ cubes, and 200 $\mathrm{mm} \times 100 \mathrm{~mm}$ cylinders) and cores taken from existing structures. For testing, first the samples were weighed on a digital weighing machine with an accuracy of $0.001 \mathrm{~kg}$, and then were tested with UPV machine. Next, the objects were clamped concentrically in CTM with vertical force with pressure of the order $5-7 \mathrm{kN} \mathrm{mm}^{-2}$ and the testing by SH was conducted. Both of the NDT were conducted as per standard procedural instructions stated in IS 13311 [17]. After finishing the SH test the vertical force was gradually increased until ultimate crushing strength was reached.

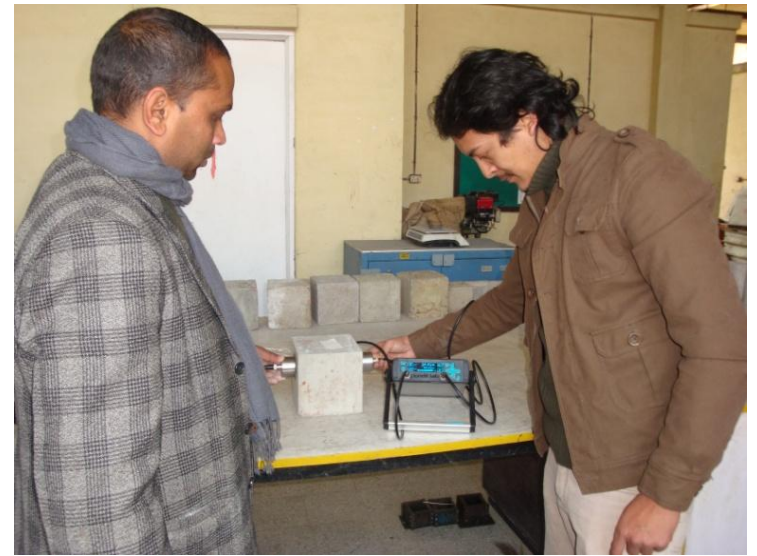

Figure 1: UPV Testing of Samples

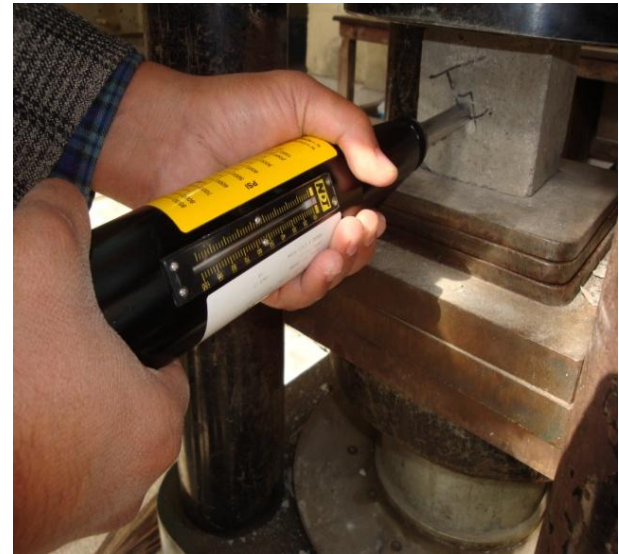

Figure 2: Reading of RN Value

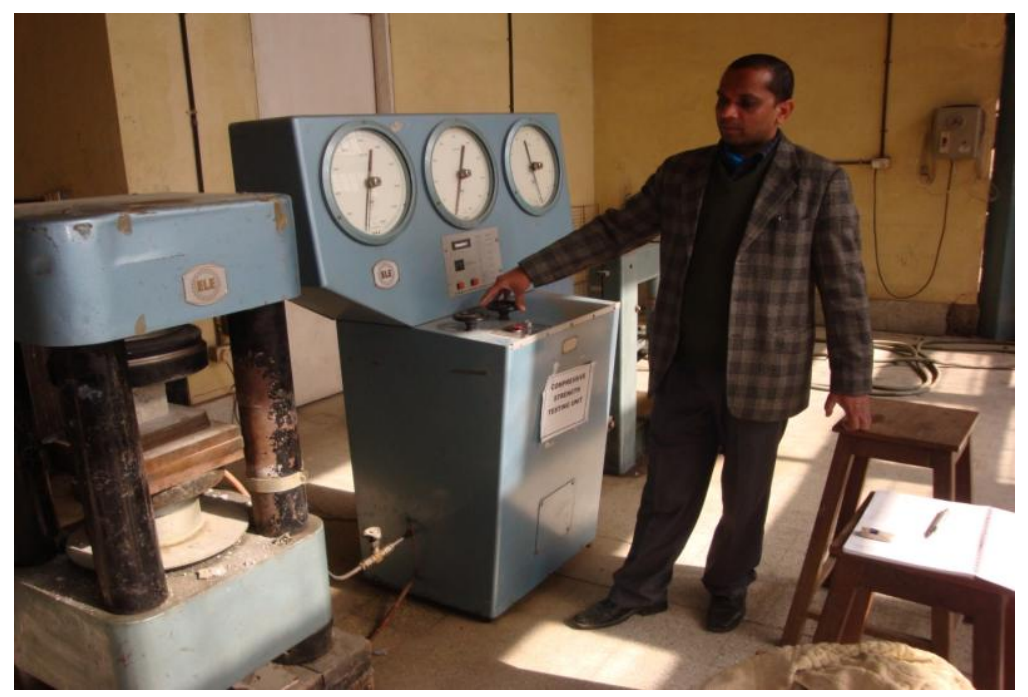

Figure 3: Determining Ultimate Crushing Load 


\section{Research Methodology}

One of the basic problems in NDT is to improve its reliability. It can be done by correlating it with the DT.

The focus is confined to the main property of concrete - compressive strength, as it is the most valuable property of concrete. The variables have been defined as the results from NDT and DT on sample objects and only NDT on the target object.

The methodology used in this research work is laboratory works and experiments based. after doing a detailed literature review, a theoretical concept regarding how to perform experiment has been developed. The main aim of this research work is to derive the relationship between Comparison of Concrete Properties determined by NDT and DT.

The tests are done as per specified rules and the results are processed statistically to determine the compressive strength of target object.

The collection of samples were done from the cubes and cylinders prepared recently by various bachelor and master level students of Institute of Engineering at Pulchowk Campus. The samples were grouped appropriately and then the tests conducted as per requirements.

\section{Result Analysis and Discussion}

The testing machines used for UPV, SH and crushing strength were same for all the testing objects. Some of the initial data obtained from tests are presented here in tabular form (Table 2)

Example: As an example testing of a $10 \mathrm{~cm}$ cube both by NDT and DT has been given and the determination of ultimate strength by different methods has been shown and compared.

Sample used as target object $T_{10}$ with the following data: (Table 1)

Cube size $10 \times 10 \mathrm{~cm}$, mass $=2.353 \mathrm{~kg}, \mathrm{SH}, \mathrm{N}$ values $=36,42,38,38,36,36,36,36,30,40$, UPV velocities, $\mathrm{v}=4081,4081,4098 \mathrm{~m} \mathrm{sec}^{-1}$.

Average $\mathrm{N}$ value, $\mathrm{N}_{\mathrm{avg}}=36.8$, Average UPV $\mathrm{v}_{\mathrm{avg}}=4086.7 \mathrm{~m} \mathrm{sec}^{-1}$,

Regression equation for $\mathrm{N}$ value from correlation data of $15 \mathrm{~cm}$ cube:

$y=0.405 x+14.98$, (see Figure 5) where $x=\mathrm{SH}$ strength according to $\mathrm{N}_{\text {avg }}$ from the $\mathrm{SH}$ (see Table 2). Here, $x=29.5$, from Table 2 .

The required strength $y=0.405 \times 29.50+14.98=26.93 \mathrm{MPa}$

Regression equation for v value from correlation data of $15 \mathrm{~cm}$ cube:

$y=0.013 x-30.63$, (see Figure 6) where $x=$ average UPV, $\mathrm{v}_{\text {avg }}$ from Table 2. Here, $x=$ 4086.7, from Table 2 .

The required strength $y=0.013 \times 4086.70-30.63=22.49 \mathrm{MPa}$ 
Table 3: Conversion of sample strengths into $15 \times 15 \mathrm{~cm}$ cube strength (Leschinkii, 1980)

\begin{tabular}{|c|c|c|c|c|c|c|c|c|c|c|c|}
\hline \multirow{2}{*}{ Sample } & \multicolumn{8}{|c|}{ Cubes $(\mathrm{cm} \times \mathrm{cm})$} & \multicolumn{7}{c|}{ Cylinders $(\mathrm{cm} \times \mathrm{cm})$} \\
\cline { 2 - 12 } & 7 & 10 & 15 & 20 & 30 & $7 \times 14$ & $10 \times 20$ & $15 \times 30$ & $20 \times 40$ & & \\
\hline$\alpha$ & 0.85 & 0.91 & 1.00 & 1.05 & 1.10 & 1.16 & 1.20 & 1.24 & & & \\
\hline \multicolumn{10}{|c|}{ For Core samples } \\
\hline $\mathrm{h} / \Phi$ & 2 & 1.9 & 1.8 & 1.7 & 1.6 & 1.5 & 1.4 & 1.3 & 1.2 & 1.1 & 1.0 \\
\hline$\eta$ & 1.2 & 1.19 & 1.18 & 1.16 & 1.14 & 1.13 & 1.12 & 1.1 & 1.09 & 1.08 & 1.07 \\
\hline
\end{tabular}

Regression equation for $N$ value from correlation data of $10 \mathrm{~cm}$ cube:

$y=0.522 x+11.56$, (see Figure 9) where $x=\mathrm{SH}$ strength according to $\mathrm{N}_{\mathrm{avg}}$ from the $\mathrm{SH}$ (see Table 2). Here, $x=29.5$, from Table 2 .

The required strength $y=0.522 \times 29.50+11.56=26.96 \mathrm{MPa}$

After converting it into $15 \times 15 \mathrm{~cm}$ cube strength, (see Table 3 ) the required strength $=26.96 \times$ $0.91=24.53 \mathrm{MPa}$

Regression equation for $v$ value from correlation data of $10 \mathrm{~cm}$ cube:

$y=0.019 x-58.47$, (see Figure 10) where $\mathrm{x}=$ average UPV, $\mathrm{v}_{\text {avg }}$ from Table 2. Here, $\mathrm{x}=$ 4086.7, from Table 2 .

The required strength $\mathrm{y}=0.019 \times 4086.70-30.63=19.18 \mathrm{MPa}$

After converting it into $15 \times 15 \mathrm{~cm}$ cube strength, (see Table 3 ) the required strength $=19.18 \times$ $0.91=17.45 \mathrm{MPa}$

Regression equation for $N$ value from correlation data of $10 \times 20 \mathrm{~cm}$ cylinder:

$y=-0.07 x+14.21$, (see Figure 13) where $x=\mathrm{SH}$ strength according to $\mathrm{N}_{\mathrm{avg}}$ from the $\mathrm{SH}$ (see Table 2). Here, $x=29.5$, from Table 2 .

The required strength $y=-0.07 \times 29.50+14.21=12.15 \mathrm{MPa}$

After converting it into $15 \times 15 \mathrm{~cm}$ cube strength, (see Table 3 ) the required strength $=12.15 \times$ $1.16=14.09 \mathrm{MPa}$

Regression equation for $v$ value from correlation data of $10 \times 20 \mathrm{~cm}$ cylinder:

$y=0.008 x-21.79$, (see Figure 14) where $x=$ average UPV, $\mathrm{v}_{\text {avg }}$ from Table 2. Here, $x=$ 4086.7, from Table 2 .

The required strength $y=0.008 \times 4086.70-21.79=10.90 \mathrm{MPa}$

After converting it into $15 \times 15 \mathrm{~cm}$ cube strength, (see Table 3 ) the required strength $=10.90 \times$ $1.16=12.64 \mathrm{MPa}$ 
Table 4: Comparison of NDT with DT for $T_{10}, 10 \times 10 \mathrm{~cm}$ cube

\begin{tabular}{|c|c|c|c|c|c|}
\hline \multirow{2}{*}{ S. N. } & \multirow{2}{*}{ Correlation with } & \multicolumn{2}{|c|}{ Strength in MPa by } & \multicolumn{2}{c|}{$\begin{array}{c}\text { Comparison with CTM } \\
\text { crushing strength in } \%\end{array}$} \\
\cline { 3 - 6 } & & SH Test & UPV Test & SH Test & UPV Test \\
\hline 1 & $15 \times 15 \mathrm{~cm}$ cube & 26.93 & 22.49 & -1.36 & -17.62 \\
\hline 2 & $10 \times 10 \mathrm{~cm}$ cube & 24.53 & 17.45 & -10.15 & -36.08 \\
\hline 3 & $10 \times 20 \mathrm{~cm}$ cylinder & 14.09 & 12.64 & -48.39 & -53.70 \\
\hline
\end{tabular}

The best result is given by correlation with $15 \times 15 \mathrm{~cm}$ cube.

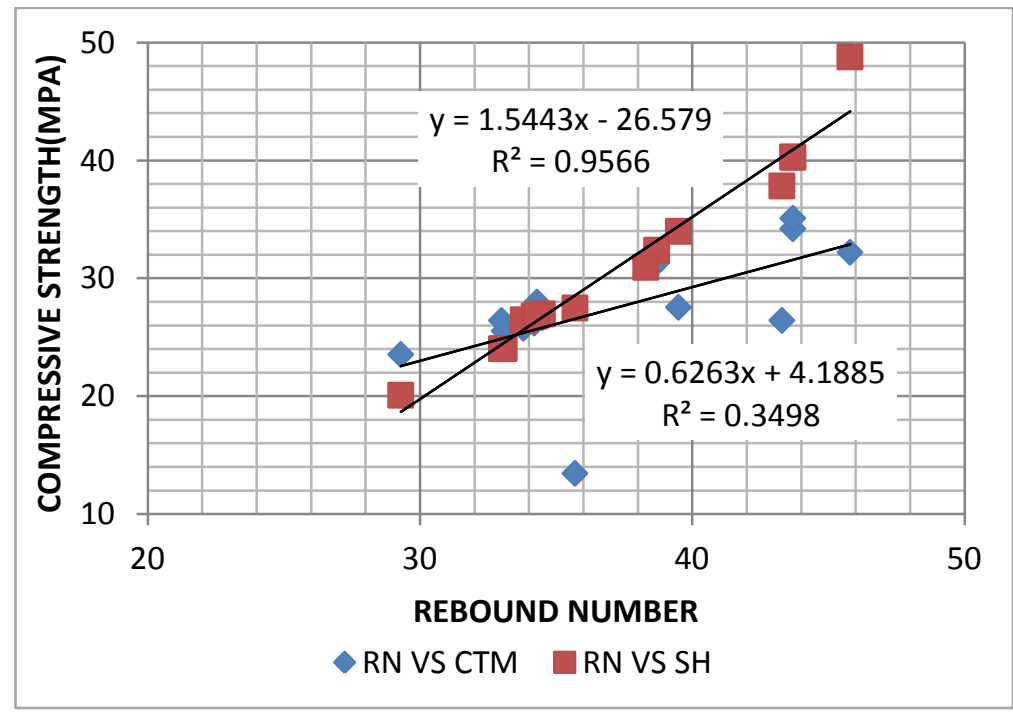

Figure 4: Rebound number versus CTM and SH strength for $150 \mathrm{~mm}$ cube samples

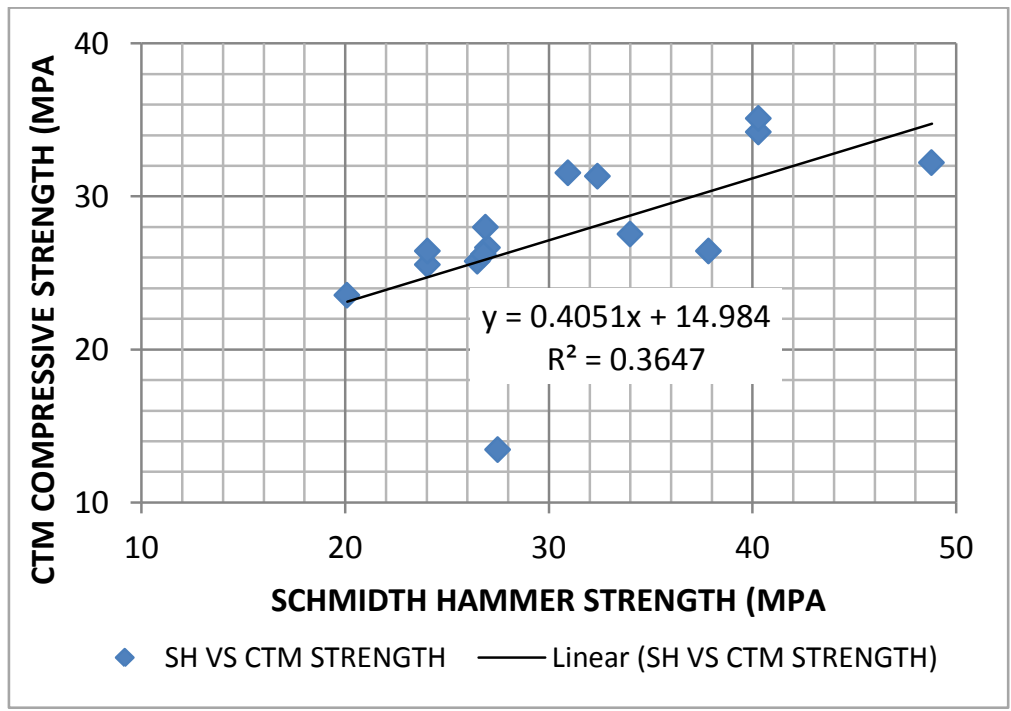

Figure 5: SH strength versus CTM strength for $15 \mathrm{~cm}$ cube samples 


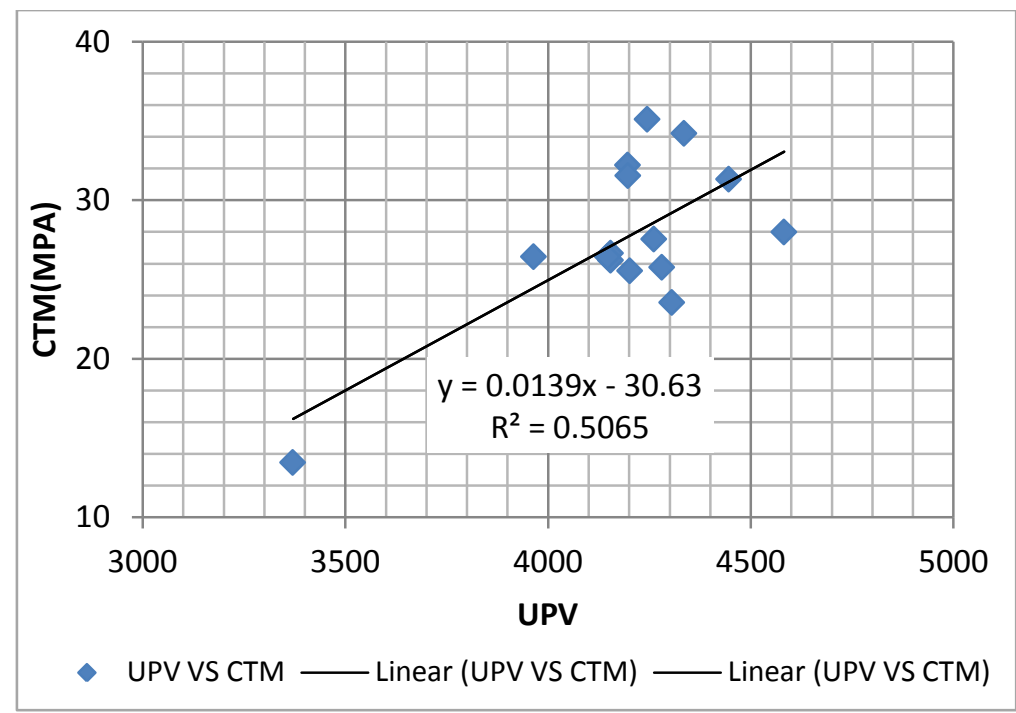

Figure 6: Ultrasonic Pulse velocity (m/s) vs compression testing machine (CTM) strength (MPA) for $150 \mathrm{~mm}$ cubes

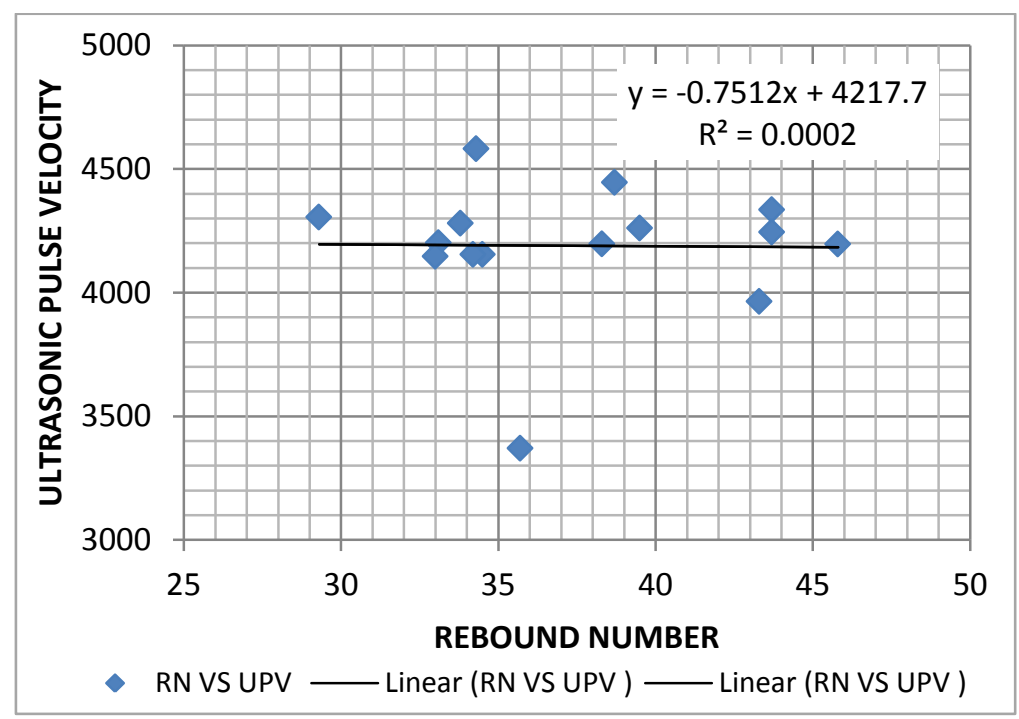

Figure 7: Rebound Number Vs ultrasonic pulse velocity $(\mathrm{m} / \mathrm{s})$ for $150 \mathrm{~mm}$ cubes

\section{Conclusions and Recommendations}

At present stage the NDTs are suitable only for controlling and estimating the compressive strength within the specified range of the target object.

i) Prior to the application of NDT, the equipment SH and UPV must have fresh referential data from DT on sample objects for comparison.

ii) The sample objects for comparison should be as close as possible to the target object in terms of expected strength and other parameters like grade, mix, type of aggregates, shape, size, age, etc. 
iii) The relationship between results of compressive strength values from NDT of the target object must be compared with those from DT and the most probable result should be taken as the final estimate.

iv) The NDTs should always be performed at least with two equipment and the results should be close enough so that the most probable one from them can be adopted.

\section{References}

[1] Ambuja Technical Literature Series -66, 2000, Commentary and Guidelines for application of IS 456: 2000, Section-2.

[2] Austin CK, 1981, Formwork Planning, 3rd edition.

[3] Aydin F and Saribiyik M, 2010; Correlation between Schmidt Hammer and destructive compressive testing for concrete in existing buildings, Scientific Research and Essays Vol 5(13), pp. 1644-1648, July 04, 2010.

[4] Concrete Rebound Hammers operators Manual, 2010, W-M-250 \& W-M-255, NDT, James Instruments Inc., Nondestructive Testing Systems.

[5] Dhir R K \& Jones M R, 2002, Innovation in concrete structure, 4th edition.

[6] Gambhir M L, 2001, Concrete Technology, 2nd edition, Tata McGraw-Hill Publishing Company Ltd. New Delhi, 8th Reprint.

[7] Hannachi S and Guetteche M N, 2012, Application of the Combined Method for Evaluating the Compressive Strength of Concrete on Site, Open Journal of Civil Engineering, 2012, 2, 16-21

[8] IS 13311 (Part 2), 1992, Non-destructive testing of concrete-methods of test, part 2, Rebound Hammer.

[9] IS 456, 2000, Explanatory Hand-book for Plain and Reinforced Concrete, fourth revision; Bureau of Indian Standards,Manak Bhawan,New Delhi.

[10] IS 456, 2000, IS Code of Practice for Plain and Reinforced Concrete, fourth revision; Bureau of Indian Standards, Manak Bhawan, New Delhi.

[11] Jain A.K, Reinforced Concrete Design, 6th edition, Nem Chand \&bros,Roorkee

[12] Joshi H R, 2005, 'Rebars and the stakeholders', Proceedings of 'National Seminar on Rebars in Civil Construction', jointly organized by Structural Engineers' Association, Nepal (SEANep) and Hama Iron and Steel Industries Pvt. Ltd., Katmandu

[13] Joshi H R, 2011, 'Earthquake and People', The Limelight, An ESGB Publication, IOE, Pulchowk Campus, Katmandu, pp 1-2.

[14] Leschinkii M Yu, 1980, Ispytanie betona: Spravochnoe posobie, (in Russian Concrrete Testing: Reference handbook), pp. (132-187).

[15] Malhotra V M \& Carino, N J, 1991, C R C Handbook on Nondestructive Testing of Concrete, Second edition ,ch-5.p.n-101-146.

[16] Malhotra V M, 2000, Advances in concrete Technology, International Conference-2000.

[17] Mehta P. Kumar and Monteiro Paulo J.M.; CONCRETE: Microstructure, properties and Material, Indian Edition(pp-17-39)

[18] Neville A M \& Brooks J J, 1999, Concrete Technology; International Student edition; Addisonwesly.

[19] Neville A M,2006, Properties of Concrete, 4th and Final edition; Pearson Edition Asia.

[20] Operating Instructions, 2010, Ultrasonic Instrument, Pundit Lab, Proceq. 
[21] Pattanaika S C, 2010, Ultra sonic pulse velocity and rebound hammer as non destructive test tools for structural health monitoring, Proceedings of International Conference NUiCONE 2010, at Institute of Technology, Nirma University, Ahemedabad from December 09-11, 2010.

[22] SHETTY M.S, 1998, CONCRETE TECHNOLOGY: Theory and Practice,S.Chand and Company Ltd.

[23] Shrestha K M, 2005, Production of very high Strength Concrete in Nepal; M.Sc. Thesis, IOE Pulchowk Campus, Dec.

[24] Taylor W H, Concrete Technology and Practice; 4th edition. (Sec-8.4(p.n.-197-198)

[25] Technical Literature, Operating Instructions Mark XII 2000 kN, 2500 kN and 3000 kN Triple Gauge Compression Machines, incorporating $50 \mathrm{kN}$ flexural and transverse frame, Engineering Laboratory Equipment Limited. 